\title{
Handball Research: State of the Art
}

\author{
by \\ Jose M. Saavedra ${ }^{1}$
}

Team handball (handball) began as a game between two teams of eleven players and was played outdoors. It has evolved into an indoor sport with seven players on each team. Handball is a popular sport played at all levels from recreational to fully professional. The modern game's origins were in Scandinavia in the early 19th century. It is today played by around 19 million people (International Handball Federation, 2014), and has been an Olympic sport since 1972 for men and since 1976 for women. In handball, there are various actions such as throws, passes, jumps, hits, blocks, pushes, runs, and dribbling (Milanese et al., 2012) that make it a contact sport of intermittent high intensity (Gorostiaga et al., 2005). Given the sport's complexity, performance in handball depends on multiple factors: anthropometric features, coordination, strength, endurance, nutrition, cognition, tactics, social factors, and external influences (Wagner et al., 2014).

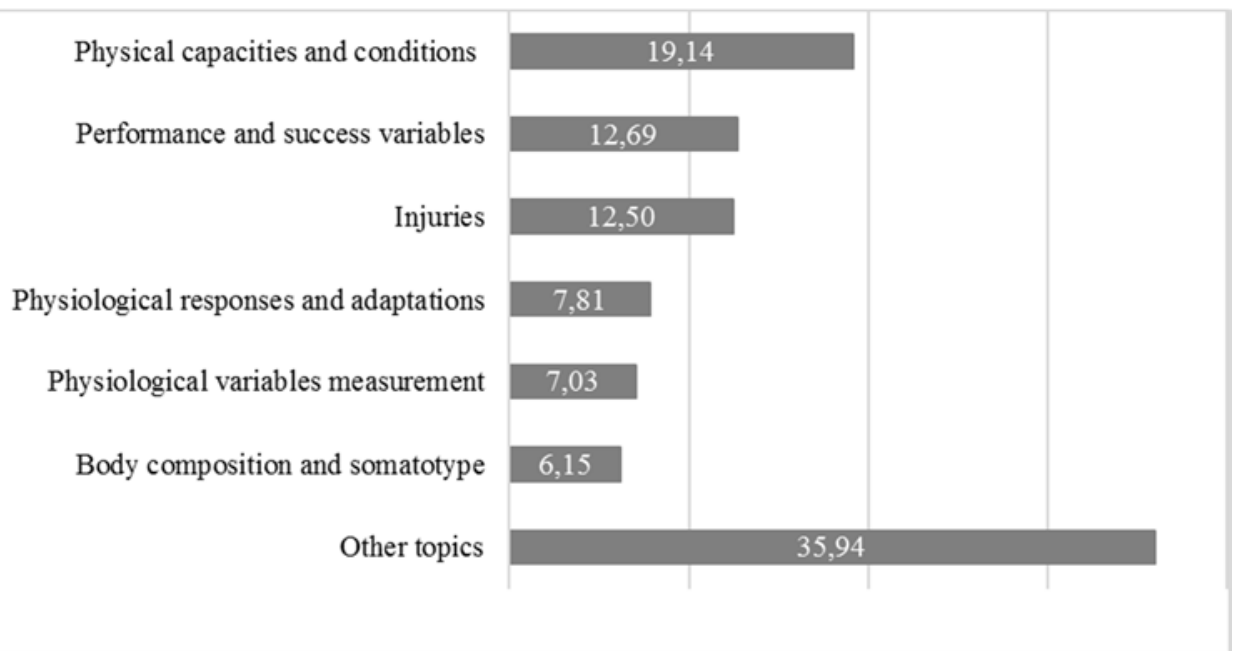

Figure 1

Percentages of the total of publications (256) in the Web of Science (Science Citation Index Expanded and Social Sciences Citation Index) from 2013 to 2018 (April 26) that correspond to each research topic.

The topics presented are based on previous works of a general nature (Sports Science)

(Devís-Devis et al., 2010), and which have also been used in handball (Prieto et al., 2015).

1 - Physical Activity, Physical Education, Sport and Health Research Centre (PAPESH), Sports Science Department, School of Science and Engineering, Reykjavik University, Reykjavik, Iceland.. 
Despite the sport's popularity, scientific publications on handball have been scarce (Saavedra et al., 2018). Indeed, to 2012, the Web of Science (1900 to 2012) and MEDLINE (1950 to 2012) databases were found (Prieto et al., 2015) to include only 373 articles with handball as the main subject, and injuries (26.5\%) along with physical capacities and conditions $(18.0 \%)$ were the research topics most studied. However, by updating the search to include works that contain the word "handball" in their title and that were published from 2013 to 2018 (April 26) in journals indexed in the Web of Science (Science Citation Index Expanded and Social Sciences Citation Index), a total of 256 articles were found (Figure 1 ), evidence of the growing scientific interest in this sport.

This increased interest in handball has led the Journal of Human Kinetics to publish this Special Issue. It comprises 15 high quality articles (there was a $50 \%$ rejection rate) involving researchers and academics from 11 countries (Australia, Belgium, Brazil, Croatia, Czech Republic, Denmark, Germany, Norway, Poland, Serbia, and Spain). Each article has been rigorously peer reviewed by at least two referees from 16 countries in addition to the 10 above: Australia, Austria, Bosnia and Herzegovina, Bulgaria, France, Greece, Iceland, Malaysia, Portugal, Romania, Slovenia, Taiwan, Tunisia, Turkey, UK, and USA. The refereeing process involved over 50 researchers and 23 institutions.

In this Special Issue, one paper analyses the influence of fouls (Fasol and Redlich, 2018), concluding that whether or not a game-stopping foul is committed has no influence on scoring a goal, and another looks at how home court advantage affects performance (Pic, 2018), finding that the potential advantage of playing at home occurs mainly in situations in which the teams reach the end of the game tied. It has to be noted, however, that physical performance in handball is different in the morning from what it is in the evening (Pavlović et al., 2018). Studies related to the national teams of two of the world's major countries in this sport - Norway and Denmark have confirmed that experience in the Norwegian national youth and junior teams is associated with the number of international matches played in the senior category (Bjorndal et al., 2018), and that the relative age effect is apparent in Danish national men's teams at these younger levels (Wrang et al., 2018). Regarding the training programs, it has been found that programs targeted at the inspiratory muscles not only improve these muscles in particular, but also contribute to enhancing aerobic performance (Hartz et al., 2018) and postural stability exercises implementing the biofeedback method on stabilo and dynamometric platforms are practical and justifiable in junior goalkeepers (Wilczyński, 2018). Pre-season conditioning programs that include working on hamstring and quadriceps muscles are needed to reduce the risk of injury (Spieszny and Zubik, 2018). Furthermore, proper planning of training in adolescents that allows them to improve their levels of strength and maximum power is necessary (Górski et al., 2018). In this way, coaches need to include a training rest period after the competitive period, to decrease the bilateral strength deficit and to support further fitness development (Gonosova et al., 2018). Analysis of the performance of Spanish handball players according to their level revealed that anthropometric characteristics of the top-elite players differ from those of the elite players, mainly in their upper limbs (Ferragut et al., 2018). On the contrary, a comparison of the Brazilian women's Olympic team and a college team found no clear differences between them in the 5, 10, 20 $\mathrm{m}$ sprint, and zig-zag test performance (Pereira et al., 2018), showing that these variables might perhaps not be decisive for the detection and/or selection of future talent. However, a metaanalysis (Serrien and Baeyens, 2018) has showed that there is a clear kinetic chain in the most relevant throws in handball, starting with pelvis rotation and followed by trunk rotation, trunk flexion, elbow extension, and shoulder internal rotation, and that this could be evaluated as a criterion in the detection of talents. Lastly, a study of the smoking and alcohol consumption habits of handball players concludes that these are not the same as those of the general population (Karnincic et al., 2018), with this sport being able to act as a protector against the risk of smoking and alcohol consumption. Also, in this Special Issue, an article (Mazurek et al., 2018) showed that a five-week pre-season conditioning programme supplemented with only 15 sessions of plyometric exercise did not offer any additional benefits in comparison with regular training. 
Finally, I wish to thank the Editor-inChief, Professor Dr Adam Zając, for the confidence and trust that have been placed in me for the preparation of this Special Issue. I would also like to thank Ms Aleksandra Mostowik (Office Manager) for her support throughout the process. I hope that the work that has been done will be to the liking of the readers of the Journal of Human Kinetics, and will allow researchers to continue to advance in scientific knowledge of handball.

\section{References}

Bjørndal CT, Luteberget LS, Holm S. The relationship between early and senior level participation in international women's and men's handball. J Hum Kinet, 2018; 63: 73-84

Devís-Devís J, Valenciano J, Villamón M, Pérez-Samaniego V. Disciplines and themes of study in physical activity and sport science. Rev Int Med Ciencias Act Fís Deporte, 2010; 10: 150-166

Fasold F, Redlich D. Foul or no foul? Effects of permitted fouls on the defence performance in team handball. J Hum Kinet, 2018; 63: 53-59

Ferragut C, Vila H, Abraldes JA, Manchado C. Influence of physical aspects and throwing velocity in opposition situations in top-elite and elite female handball players. J Hum Kinet, 2018; 63: 23-32

Gonosova Z, Stastny P, Belka J, Bizovska L, Lehnert M. Muscle strength variations of knee joint muscles in elite female handball players after pre-season conditioning. J Hum Kinet, 2018; 63: 105-115

Gorostiaga EM, Granados C, Ibanez J, Izquierdo M. Differences in physical fitness and throwing velocity between elite and amateur male handball players. Int J Sports Med, 2005; 26: 225-232

Górski M, Starczewski, M, Pastuszak A, Mazur-Różycka J, Gajewski J, Buśko K. Changes of strength and maximum power of lower extremities in adolescent handball players during a two-year training cycle. $J$ Hum Kinet, 2018; 63:95-103

Hartz CS, Sindorf MAG, Lopes CR, Batista J, Moreno MA. Effect of inspiratory muscle training on the performance of handball athletes. J Hum Kinet, 2018; 63: 43-51

International Handball Federation. (2014). Handball. History and stories. Retrieved 15th April 2018, from http://techcrunch.comhttp://ihf.info/upload/Book/issue0001/index.html

Karnincic H, Cavala M, Rogulj N. The relationship between handball players and alcohol and smoking habits. J Hum Kinet, 2018; 63: 127-136

Mazurek K, Zmijewski P, Makaruk H, Mróz A, Czajkowska A, Witek K, Bodasiński S, Lipińska P. Effects of short-term plyometric training on physical performance in male handball players. J Hum Kinet, 2018; 63: $137-148$

Milanese C, Piscitelli F, Lampis C, Zancanaro C. Effect of a competitive season on anthropometry and threecompartment body composition in female handball players. Biol Sport, 2012; 29: 199-204

Pavlović L, Stojiljković N, Aksović N, Stojanović E, Valdevit Z, Scanlan AT, Milanović Z. Diurnal variations in physical performance: Are there morning-to-evening differences in elite male handball players? J Hum Kinet, 2018; 63: 117-126

Pereira LA, Cal Abad CC, Kobal R, Kitamura K, Orsi RC, Ramirez-Campillo R, Loturco I. Differences in speed and power capacities between female National college team and National Olympic team handball athletes. J Hum Kinet, 2018; 63: 85-94

Pic M. Performance and home advantage in handball. J Hum Kinet, 2018; 63: 61-71

Prieto J, Gómez MA, Sampaio J. A bibliometric review of the scientific production in handball. Cuadernos Psicol Deporte, 2015; 15: 145-154

Saavedra JM, Porgeirsson S, Chang M, Kristjánsdóttir H, García-Hermoso, A. Discriminatory power of women's handball game-related statistics at the Olympic Games (2004-2016). J Hum Kinet, 2018; 62: 221-229

Serrien B, Baeyens JP. Systematic review and meta-analysis on proximal-to-distal sequencing in team handball: Prospects for talent detection? J Hum Kinet, 2018; 63: 9-21

Spieszny, M, Zubik M. Modification of strength training programs in handball players and its influence on power during the competitive period. J Hum Kinet, 2018; 63: 149-160 
Wagner H, Finkenzeller T, Würth S, von Duvillard SP. Individual and Team Performance in Team-Handball: A Review. J Sports Sci Med, 2014; 13: 808-816

Wilczyński J. Postural stability in goalkeepers of the Polish National Junior Handball Team. J Hum Kinet, 2018; 63: 161-170

Wrang CM, Rossing NN, Diernæs RM, Hansen CG, Dalgaard-Hansen C, Karbing DS. Relative age effect and the progression of Danish male handball players in national teams. J Hum Kinet, 2018; 63: 33-41

\section{Corresponding author:}

\section{Jose M. Saavedra}

Physical Activity, Physical Education, Health and Sport Research Centre (PAPESH). School of Science and Engineering. Reykjavik University. Menntavegur 1, Nauthólsvík, 101 Reykjavík, Iceland.

Phone: +354 5996200

Fax + 3545996201

Email: saavedra@ru.is 